\title{
Optimization of odour-baited resting boxes for sampling malaria vector, Anopheles arabiensis Patton, in arid and highland areas of Africa
}

\author{
Eliningaya J Kweka ${ }^{1 *}$, Beda J Mwang'onde ${ }^{1}$, Aneth M Mahande ${ }^{2}$
}

\begin{abstract}
Background: Odour baited resting boxes are simple, reliable and important tools for sampling malaria vector mosquitoes in surveillance and control programmes in different parts of Africa. To optimize the use of cow urine baited resting boxes for sampling An. arabiensis, a community-based study was conducted in Mabogini hamlet in the Lower Moshi irrigation scheme area.

Method: Experimental designs using 3 by 3 Latin square were conducted for twenty days to evaluate the following: i) the effect of different parameters in the sampling of mosquitoes using odour baited resting boxes; ii) the performance of odour baited traps under indoor and outdoor conditions and the effect of people sleeping indoors on mosquito density; iii) the effect of position in the placement of traps on collection of mosquitoes; and, iv) the efficiency of the trap outdoors at three different distances from the house wall. One extra house served as the sentinel house to monitor species abundance using a CDC-miniature light trap.

Results: 8581 mosquitoes were sampled by odour baited resting boxes of which, 8051 (93.82\%) were An. arabiensis and $530(6.18 \%)$ Cx. quinquefasciatus. The light trap collected 12,420 mosquitoes, of which 9442 (76.02\%) were An. arabiensis, 126 (1.01\%) An. funestus group, 230 (1.85\%) An. rufipes and 2622 (21.11\%) Cx. quinquefasciatus. The best height for outdoor mosquitoes sampling was $15 \mathrm{~cm}$ and $220 \mathrm{~cm}$ while indoors was $105 \mathrm{~cm}$. The difference in mosquito collection between different outdoor and indoor heights was statistically significant $(p<$ 0.0001). The optimal outdoor location of odour baited resting boxes from the wall of the house was $3 \mathrm{~m}$.
\end{abstract}

Conclusions: The results of these studies demonstrate an optimal method for sampling during surveillance and control programmes in rural villages of highlands and arid areas of Africa using inexpensive baits and boxes.

\section{Background}

Hematophagus insects locate their hosts following odours emanated by the hosts [1-5]. The Anopheles gambiae complex comprises two major malaria vector species An. gambiae Giles and An. arabiensis Patton while the An. funestus group include the major malaria vector, An. funestus Giles [6]. All three species are abundant in sub-Saharan Africa [6]. An. gambiae ss are anthropophilic while An. arabiensis are both anthropophilic as well as zoophilic depending on geographical location [6,7]. Human sweats and other animal body products attract haematophagus insects, such as tsetse

\footnotetext{
* Correspondence: pat.kweka@gmail.com

'Tropical Pesticides Research Institute, Division of Livestock and Human Diseases Vectors Control, Mosquito Section, P.O.Box 3024, Arusha, Tanzania Full list of author information is available at the end of the article
}

flies [8,9]; mosquitoes [10-13] and sand flies [14]. Knowledge of these attractants plays a vital role in reducing human vector contact and in conducting surveillance studies. Resting boxes, either baited or un-baited, have been demonstrated to be suitable for the sampling of malaria vectors in different parts of Africa $[15,16]$. Fresh or decayed cattle urine baited resting boxes are effective in sampling An. Arabiensis, with efficacy even after seven days post-treatment $[15,17]$.

This study deployed the fresh cattle urine in wet black cotton cloth to study the optimal trap placement and validate the effectiveness of the methodology. Three sets of experiments were conducted to determine: i) if traps with urine as bait perform better indoors or outdoors, and if people sleeping indoors had effects on the mosquito density; ii) the best height of trapping mosquitoes 
indoors and outdoors; and iii) the efficiency of the trap located in three different distances from the wall of the house.

\section{Materials and methods}

\section{Study Area Description}

The study was conducted during the paddy transplantation season in the lower Moshi irrigation schemes, located $15 \mathrm{Km}$ southern part of Moshi Town at the foot of the slopes of Mount Kilimanjaro, Northern Tanzania $\left(3^{\circ} 21^{\prime} \mathrm{S}, 37^{\circ} 21^{\prime} \mathrm{E}\right)$. The study area is shown in Figure 1.

\section{House selection and characterization}

Ten houses were surveyed during the preparation stage of the study using CDC-miniature light traps for collecting mosquitoes from the surveyed houses. Four houses with high mosquito density were selected for the main study. In these selected houses, parameters such as eave

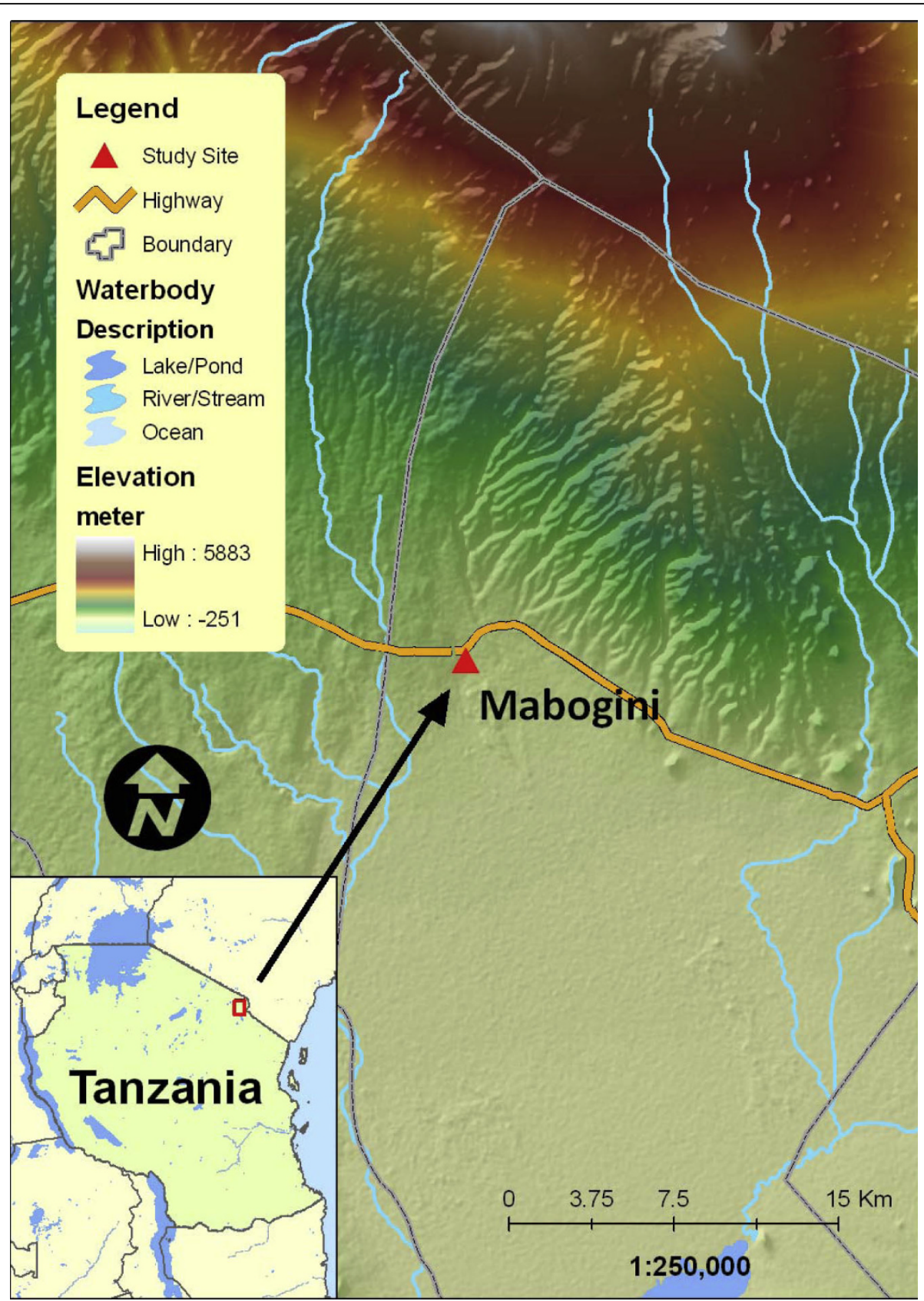

Figure 1 Map showing the area where the sampling was performed at Point $D$ in Lower Moshi irrigation schemes in Northern Tanzania. 
sizes, number of windows, wall and roof types and number of people sleeping in the house during experimental nights were recorded and compared with indoor mosquito density.

\section{Experimental design}

The study was a cross-sectional design in 3 by 3 -Latin square for 20 days with an extra house fitted with CDC light trap for mosquitoes species abundance monitoring. One replicate was conducted for a period of three days; the study had a total of 6 replicates for 18 days. Two extra days were added to complement the lost time in two experimental days. In the first experiment, two baited resting boxes were used indoors and outdoors and placed at three different heights: $15 \mathrm{~cm}(\mathrm{H} 1) ; 105 \mathrm{~cm}$ (H2); and $220 \mathrm{~cm}(\mathrm{H} 3)$. Each house was used with one pair of boxes per night at one height.

The second experiment was designed to determine the optimal outdoor location for odour baited resting boxes by selecting three distances from the external wall of the house: $0.3 \mathrm{~m} ; 3 \mathrm{~m}$; and $5 \mathrm{~m}$. Each distance was tested per house per night in 3 by 3 Latin square for 20 days. The experiments were conducted for a period of twenty days between January and February, 2010.

\section{Animal husbandry, urine collection and preparation of the boxes}

Urine was collected in the morning from a mature female zebu cow and stored in a refrigerator at $4^{\circ} \mathrm{C}$ until the start of the experiment on the same evening. Boxes were prepared as previously described $[15,17]$.

\section{Mosquito sampling}

Trapping of mosquitoes by odour baited resting boxes and CDC-miniature light trap started at 1800 hours. The trapped mosquitoes were collected at 0600 hours in the following morning using a mechanical aspirator from the odour baited resting boxes and transferred to labelled cups. The Identification key [7] was used to identify mosquitoes in the laboratory. The abdominal conditions were identified as per World Health Organization manual [18].

\section{Statistical Analysis}

Data were encoded in Excel spreadsheet before exporting to PWAS Statistics 18.0 (SPSS Inc., Chicago, IL) for analysis. Due to the high variability in mosquito density in each sampling point, all data were log transformed $(\log (n+1))$ before analysis to normalise the data. General linear model univariate analytical procedure was used to assess the effect of odour baited resting boxes at different heights, house position and days of mosquito sampling. Paired sample T-test was used to compare the density of mosquitoes collected indoors and outdoors in odour baited resting boxes. ANOVA test was used to compare the density differences of mosquitoes with the height of the traps from indoor and outdoor locations. ANOVA was also used to compare the variations of mosquitoes density collected from different distances from the experimental house walls $(0.3 \mathrm{~m}, 3 \mathrm{~m}$ and $5 \mathrm{~m}$ ) and paired t-test was used to compare the mean density between each distance. The effect of the evaluated sampling tool was considered to be significant at $\mathrm{p}<0.05$.

\section{Ethical considerations}

The Ethics Committee of the Tropical Pesticides Research Institute approved the study. The objectives of the study were discussed with residents of the hamlet and a signed written consent was obtained from the head of each participating household.

\section{Results}

Mosquito species abundance, house characteristics and factors associated with variation in mosquito density The CDC-miniature light trap sampled 12,420 mosquitoes of which 9,442 (76.02\%) were An. gambiae s.l, 126 (1.01\%) An. funestus group, 230 (1.85\%) An. rufipes and 2,622 (21.11\%) Cx.quinquefasciatus (Additional file 1: Table S1). Odour baited resting boxes collected 8581 mosquitoes of which, 8,051 (93.82\%) were An. gambiae s.l and $530(6.18 \%)$ were Cx. quinquefasciatus (Additional file 2: Table S2). All An. gambiae s.l collected were considered as An. arabiensis according to previous molecular identification done by Ijumba, et al [19] in the same study area. The abdominal conditions of all $A n$. arabiensis from the CDC light trap were unfed while those from odour baited resting boxes had different abdominal conditions (Table 1). The experimental houses all represented the typical characteristics of the traditional houses found in lower Moshi irrigation scheme (Table 2).

The mosquito density collected by CDC light trap in one house and resting boxes in three houses varied significantly, mainly due to the vertical (height) positioning of the trap in both indoor and outdoor (DF $=3, \mathrm{~F}=$ 26.034, $\mathrm{p}<0.0001)$. The number of days had no effect for both indoor ( $\mathrm{DF}=19, \mathrm{~F}=0.959, \mathrm{P}=0.694$ ) and outdoor $(\mathrm{DF}=19, \mathrm{~F}=1.771, \mathrm{P}=0.113)$ positions. The location of house also had no effect on density of mosquitoes indoor $(\mathrm{DF}=3, \mathrm{~F}=0.866, \mathrm{p}=0.464)$ and outdoor $(\mathrm{DF}=3, \mathrm{~F}=1.198, \mathrm{P}=0.319)$.

\section{Performance of the trap between outdoor, indoor, and effect of human inhabitants sleeping indoors}

The indoor and outdoor mean densities (95\% confidence intervals in parenthesis) were found to be 0.81 (0.64$0.98)$ and 2.14(1.97-2.41), respectively. The densities of 
Table 1 Abdominal conditions of female An. arabiensis and Cx. quinquefasciatus sampled by light trap and odour baited resting boxes in selected houses

\begin{tabular}{llllll}
\hline Method & Species & Unfed & Fed & Semi gravid & Gravid \\
\hline CDC light trap & An. arabiensis & $9442(44.97 \%)$ & 0 & 0 & 0 \\
\cline { 2 - 6 } & An. funestus group & $126(0.60 \%)$ & 0 & 0 & 0 \\
\cline { 2 - 6 } & An.rufipes & $320(1.52 \%)$ & 0 & 0 & 0 \\
\cline { 2 - 6 } & Cx. quinquefasciatus & $2532(12.06 \%)$ & $3119(14.89 \%)$ & $2984(14.21 \%)$ & $1128(5.37 \%)$ \\
\hline Odour baited resting boxes & An. arabiensis & $820(3.90 \%)$ & $94(0.45 \%)$ & $220(1.05 \%)$ & $36(0.17 \%)$ \\
\cline { 2 - 6 } & Cx. quinquefasciatus & $180(0.86 \%)$ & & & 0 \\
\hline
\end{tabular}

The percentage is derived from overall sampled mosquitoes by both methods

An. gambiae s.l mosquitoes sampled indoor and outdoor using odour baited resting boxes were statistically different $(t=4.477, D F=59, P<0.0001)$. The overall indoor mosquito density was higher than outdoor.

\section{Optimal height of placement of resting boxes in indoor and outdoor conditions}

The height of the odour baited resting boxes had an impact on the number of collected mosquitoes in both indoor $(\mathrm{DF}=2, \mathrm{~F}=143.607, \mathrm{P}<0.0001)$ and outdoor ( $\mathrm{DF}=2, \mathrm{~F}=180.986, \mathrm{P}<0.0001$ ) locations. Indoors, H2 $(105 \mathrm{~cm})$ positioned odour baited resting boxes collected more mosquitoes than $\mathrm{H} 1(15 \mathrm{~cm})$ and $\mathrm{H} 3(220 \mathrm{~cm})$. Outdoors, $\mathrm{H} 1$ sampled more mosquitoes than $\mathrm{H} 3$ while H2 sampled no mosquitoes (Figure 2). In using paired t-test for sampled means, the difference between indoor resting boxes, $\mathrm{H} 1$ and $\mathrm{H} 2$ was significant ( $\mathrm{p}<0.0001)$. The same was true for $\mathrm{H} 2$ and $\mathrm{H} 3(\mathrm{p}<0.0001)$ and for $\mathrm{H} 1$ and $\mathrm{H} 3$ too $(\mathrm{P}=0.05)$. In the outdoor positions, the difference between $\mathrm{H} 1$ and $\mathrm{H} 2(\mathrm{P}<0.0001)$ and for $\mathrm{H} 2$ and H3 ( $\mathrm{p}<0.0001)$ was significant. However, H1 and H3 showed no significant differences $(P=0.08)$.

Efficiency of the trap in collecting outdoor mosquitoes at different distances from the house

The number of mosquitoes collected from the baited resting boxes placed at $0.3 \mathrm{~m}, 3 \mathrm{~m}$ and $5 \mathrm{~m}$ from the wall of the house were statistically significant $(\mathrm{DF}=2$, $\mathrm{F}=17.3592, \mathrm{P}<0.0001)$. In comparing densities between distances with t-test paired two samples of means, the density difference between $0.3 \mathrm{~m}$ and $3 \mathrm{~m}$ was significantly different $(\mathrm{df}=59, \mathrm{t}=1.67, \mathrm{p}<0.0001)$ while $0.3 \mathrm{~m}$ and $5 \mathrm{~m}$ was not significant $(\mathrm{df}=5, \mathrm{t}=$ 1.67, $\mathrm{p}=0.09$ ). The number of mosquitoes collected at $3 \mathrm{~m}$ and $5 \mathrm{~m}$ were significantly different $(\mathrm{df}=5, \mathrm{t}=$ 1.67, $\mathrm{p}<0.0001$ ). The highest density of mosquitoes was found in odour baited resting boxes placed at $3 \mathrm{~m}$ away from the wall of each house (Figure 3 and Additional file 3: Table S3).

\section{Discussion}

This study has shown that a resting box baited with cattle urine odour is efficient in collecting female $A n$. arabiensis and $C x$. quinquefasciatus. This efficiency is dependent upon the height at which the resting boxes are placed for indoors and outdoors and the distance from the wall of the house. The addition of cattle urine in resting boxes showed significant improvement in the efficiency of the traps in collecting mosquitoes. These observations are similar to the observations obtained from previous studies $[15,17]$. The number of people sleeping in the house, house positions and days of collections had no effect. The presence of odour baited resting boxes did not represent a nuisance to people sleeping on their beds. The outside baited resting boxes had more mosquitoes (An. gambiae s.l) at the height of $15 \mathrm{~cm}$ and at $220 \mathrm{~cm}$ (eave position) than at $105 \mathrm{~cm}$ (window position, at intermediate height). The highest density for indoor sampling was at the height of $105 \mathrm{~cm}$ (window position) compared to $15 \mathrm{~cm}$ and $220 \mathrm{~cm}$. This

Table 2 Characteristics of houses used in the evaluation of odour baited resting boxes

\begin{tabular}{|c|c|c|c|c|c|c|c|}
\hline $\begin{array}{l}\text { House } \\
\text { ID }\end{array}$ & $\begin{array}{l}\text { Number of occupants/ } \\
\text { night }\end{array}$ & $\begin{array}{l}\text { Light and Fuel } \\
\text { source }\end{array}$ & $\begin{array}{l}\text { Roof } \\
\text { type }\end{array}$ & Wall type & $\begin{array}{l}\text { Eave size } \\
(\mathrm{cm})\end{array}$ & $\begin{array}{l}\text { Number of windows per } \\
\text { room }\end{array}$ & $\begin{array}{l}\text { Cooking } \\
\text { place }\end{array}$ \\
\hline HS1 & 3 & $\begin{array}{l}\text { Kerosene and } \\
\text { charcoal }\end{array}$ & $\begin{array}{l}\text { Iron } \\
\text { sheets }\end{array}$ & Mud wall & 15 & 1 & outdoors \\
\hline HS2 & 4 & $\begin{array}{l}\text { Kerosene and } \\
\text { firewood }\end{array}$ & $\begin{array}{l}\text { Iron } \\
\text { sheets }\end{array}$ & Burnt bricks & 13 & 2 & outdoors \\
\hline $\mathrm{HS} 3$ & 6 & $\begin{array}{l}\text { Kerosene and } \\
\text { firewood }\end{array}$ & $\begin{array}{l}\text { Iron } \\
\text { sheets }\end{array}$ & Burnt bricks & 10 & 1 & outdoors \\
\hline HS4 & 4 & $\begin{array}{l}\text { Kerosene and } \\
\text { charcoal }\end{array}$ & $\begin{array}{l}\text { Iron } \\
\text { sheets }\end{array}$ & $\begin{array}{l}\text { Cement } \\
\text { bricks }\end{array}$ & 21 & 1 & outdoors \\
\hline
\end{tabular}




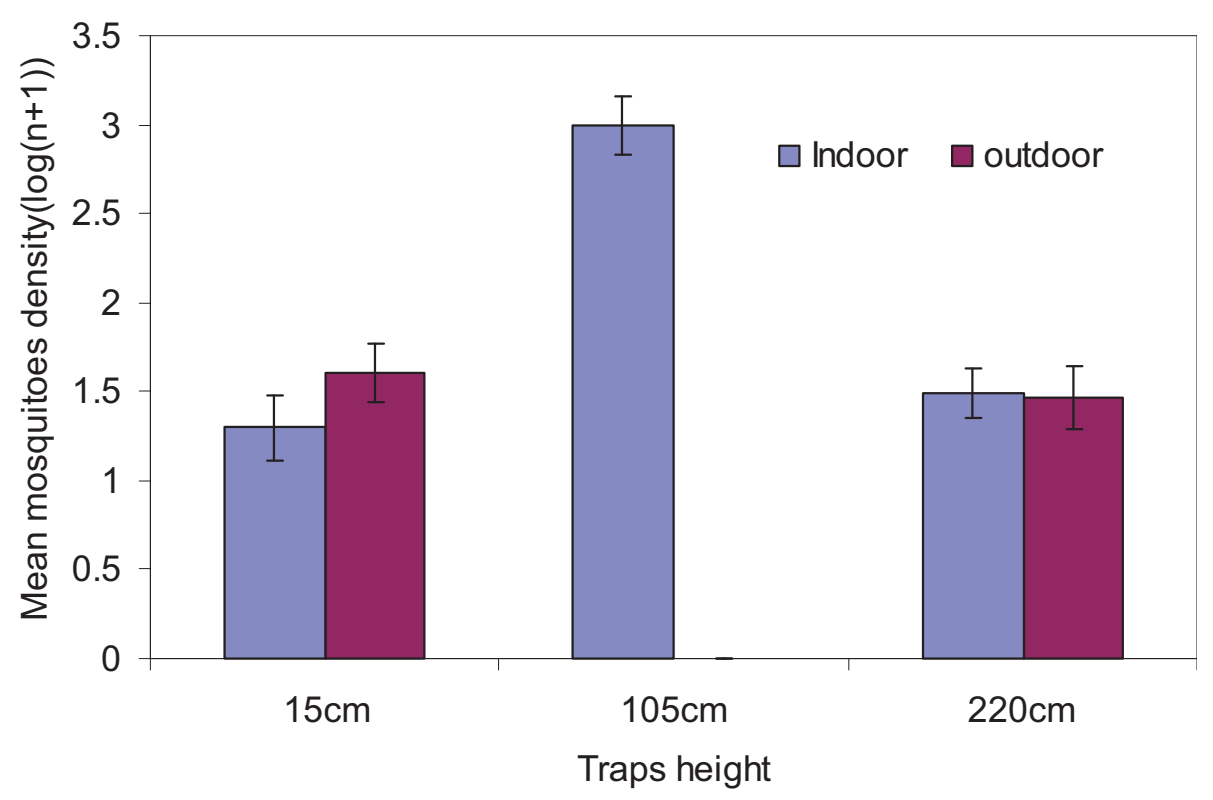

Figure 2 The mean number of mosquitoes collected at different heights for both indoor and outdoor using the odour baited resting boxes.

effect may result from incoming morning sunshine through the gaps in the window that may have caused most of the mosquitoes to fly out and trapped resting in traps. The boxes placed at $3 \mathrm{~m}$ away from the house wall had higher density than those placed at $0.3 \mathrm{~m}$ and $5 \mathrm{~m}$ (Figure 3). For optimal use, it is advised to place the odour baited resting boxes for trapping An. arabiensis along the window level during indoor sampling and $15 \mathrm{~cm}$ and adjacent to the eave position for outdoors.
The $3 \mathrm{~m}$ distance from the house wall is recommended for placing odour baited resting boxes for efficient trapping of An. arabiensis seeking foraging places.

Further studies are needed to integrate baits, such as cattle urine, and entomopathogenic fungi or non-repellent insecticides in order to pave the way towards better control of malaria. Non-irritant insecticides and entomopathogenic fungi are effective against mosquitoes in both laboratory and field evaluation [20-24]. The

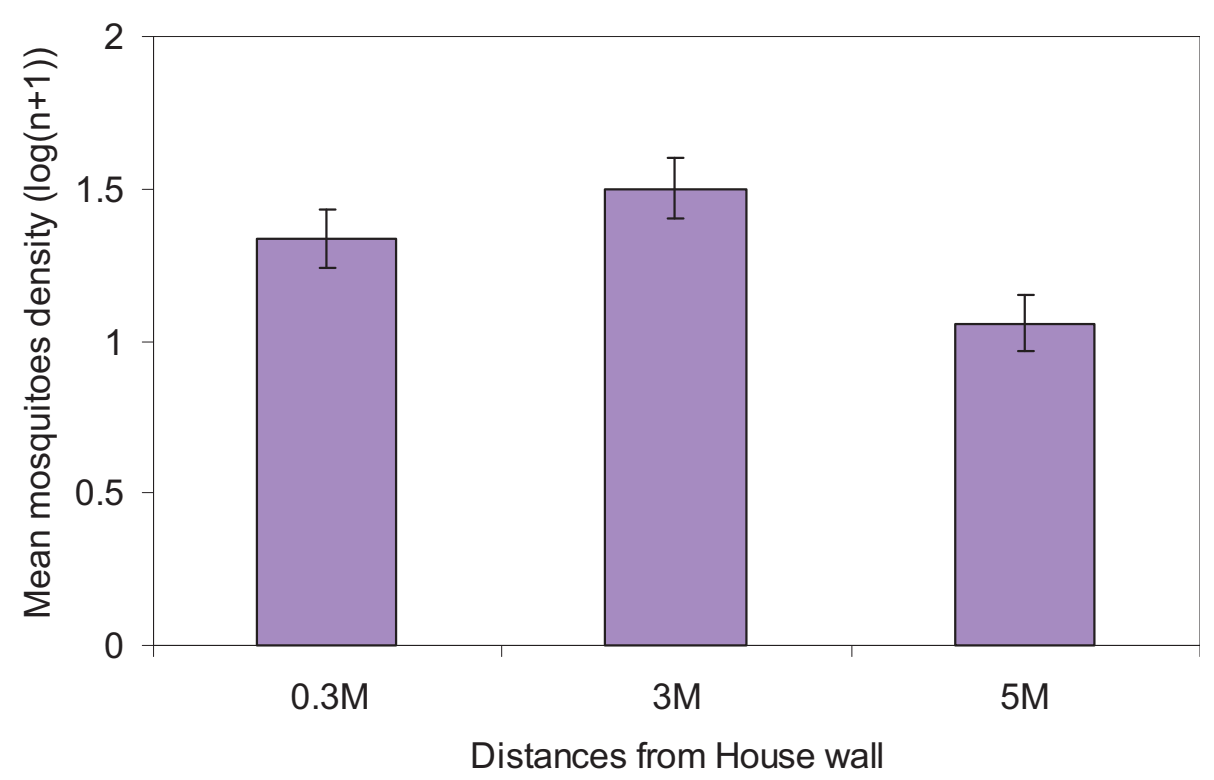

Figure 3 The mean variation of mosquitoes sampled outdoors at different distances from the house wall. 
treatment of the odour baited resting boxes with insecticides and fungus and its placement in optimal positions can play a major role in increasing mosquito mortality. Once these odour baited boxes are deployed, other factors for reducing entry of mosquitoes, such as house modifications, should be emphasized [25,26].

The CDC-miniature light traps are more efficient than the baited resting boxes in the density and diversity of species of mosquitoes collected. However, baited resting boxes are better in sampling fed and gravid mosquitoes, which are more important in addressing malaria transmission in terms of blood meal sources and parity rates (Table 1). The urine baited traps provide a useful alternative tool for sampling malaria vector mosquitoes. This method can also be useful to infect blood fed, semi and full gravid mosquitoes with entomopathogenic fungi $[20,24]$. The higher density of semi-gravid and gravid mosquitoes using this baiting method is useful in evaluating oviposition behavior of malaria vectors and in determining the best control method in targeting ovipositing mosquitoes.

This study demonstrated the optimal height and distance from the house wall for surveillance or the control of An. arabiensis that may find use in different highlands and arid areas of African where these vectors dominate. This methodology is also promising because it allows sampling of mosquito vectors without risking human volunteers to infectious mosquito bites. The boxes and cow urine are easily accessible locally and are abundant in rural communities where the method is potentially useful. The trap does not need skilled personnel to operate and are environmentally friendly. Because these traps collect live mosquitoes, they can be used in biological studies to raise colonies for studies on parity rates, insecticidal susceptibility and other scientific/research interests.

\section{Conclusion}

This study demonstrated the usefulness of odour baited boxes for sampling mosquitoes and the optimum location for placement in indoor and outdoor positions. Optimal collection rates outdoors was at a distance of $3 \mathrm{~m}$ from house wall. The best height in outdoor placement was $15 \mathrm{~cm}$ and $220 \mathrm{~cm}$ while for indoor was $105 \mathrm{~cm}$.

\section{Additional material}

Additional file 1: Supplementary Table S1: Total female mosquitoes collected by CDC light trap for 20 days of monitoring the mosquito densities in houses.

Additional file 2: Supplementary Table S2: The total number of female mosquitoes collected by Odour Baited Resting Boxes (OBRB) at different heights for both indoor and outdoors for 20 days.
Additional file 3: Supplement Data Table S3: The number of the female An. arabiensis sampled during 20 days of experiments by odour baited resting boxes placed outdoors at different distances from the wall of each house.

\section{Acknowledgements}

We wish to thank the community members who allowed us to use their houses during the study period and the owner of the zebu cow for assisting in the daily collection of urine. We would also wish to thank Mr. Charles Massenga and Augustine Mtui for their tireless work in sorting and identifying the collected mosquitoes. Dr. Jonathan R. Matias of Poseidon Science Foundation (USA) is acknowledged for his constructive comments during the preparation of this manuscript. The authors also acknowledge the assistance of Tropical Pesticides Research Institute in providing the resources and manpower from Mabogini Field Station to supervise and perform these experiments. The Director General of TPRI is acknowledged for her support in this study.

\section{Author details}

${ }^{1}$ Tropical Pesticides Research Institute, Division of Livestock and Human Diseases Vectors Control, Mosquito Section, P.O.Box 3024, Arusha, Tanzania. ${ }^{2}$ Tropical Pesticides Research Institute, Mabogini Field Station, Moshi, Tanzania.

\section{Authors' contributions}

EJK conceived and designed the experiments, analyzed and interpreted the data. BJM and MAM performed the experiments. EJK and BJM wrote the paper. All authors approved the manuscript for submission.

\section{Competing interests}

The authors declare that they have no competing interests.

Received: 20 June 2010 Accepted: 19 August 2010

Published: 19 August 2010

\section{References}

1. Carey AF, Wang G, Su CY, Zwiebel L, Carlson JR: Odorant reception in the malaria mosquito Anopheles gambiae. Nature 2010, 464:66-71.

2. Knols BG, de Jong $R$, Takken W: Differential attractiveness of isolated humans to mosquitoes in Tanzania. Trans R Soc Trop Med Hyg 1995, 89:604-606.

3. Mboera LE, Knols BG, Takken W, Huisman PW: Olfactory responses of female Culex quinquefasciatus Say (Diptera: Culicidae) in a dual-choice olfactometer. J Vector Ecol 1998, 23:107-113.

4. Takken W, Knols BG: Odor-mediated behavior of Afrotropical malaria mosquitoes. Annu Rev Entomol 1999, 44:131-157.

5. Zwiebel $\mathrm{L}$, Takken W: Olfactory regulation of mosquito-host interactions. Insect Biochem Mol Biol 2004, 34:645-652.

6. Coetzee $M$, Craig M, le Sueur D: Distribution of African malaria mosquitoes belonging to the Anopheles gambiae complex. Parasitol Today 2000, 16:74-77.

7. Gillies TM, Coetzee M: Supplement of the Anopheles of Africa South of Sahara (Afrotropical Region). Johannesburg, Republic of South Africa Publication of The S Afr Insti Med Research 1987, 143.

8. Knols BG, Willemse L, Flint $S$, Mate A: A trial to control the tsetse fly, Glossina morsitans centralis, with low densities of odour-baited targets in west Zambia. Med Vet Entomol 1993, 7:161-169.

9. Willemse $L P$, Takken $W$ : Odor-induced host location in tsetse flies (Diptera: Glossinidae). J Med Entomol 1994, 31:775-794.

10. Braks MA, Anderson RA, Knols BG: Infochemicals in mosquito host selection: human skin microflora and Plasmodium parasites. Parasitol Today 1999, 15:409-413.

11. de Jong R, Knols BG: Olfactory responses of host-seeking Anopheles gambiae s.s. Giles (Diptera: Culicidae). Acta Trop 1995, 59:333-335.

12. Knols BG: On human odour, malaria mosquitoes, and limburger cheese. Lancet 1996, 348:1322. 
13. Olanga EA, Okal MN, Mbadi PA, Kokwaro ED, Mukabana WR: Attraction of Anopheles gambiae to odour baits augmented with heat and moisture. Malar J 2010, 9:6.

14. Bray DP, Hamilton JG: Host odor synergizes attraction of virgin female Lutzomyia longipalpis (Diptera: Psychodidae). J Med Entomol 2007, 44:779-787.

15. Kweka EJ, Mwang'onde BJ, Kimaro E, Msangi S, Massenga CP, Mahande AM: A resting box for outdoor sampling of adult Anopheles arabiensis in rice irrigation schemes of lower Moshi, northern Tanzania. Malar J 2009, 8:82.

16. Odiere M, Bayoh MN, Gimnig J, Vulule J, Irungu L, Walker E: Sampling outdoor, resting Anopheles gambiae and other mosquitoes (Diptera:

Culicidae) in western Kenya with clay pots. J Med Entomol 2007, 44:14-22.

17. Mahande AM, Mwang'onde BJ, Msangi S, Kimaro E, Mnyone LL, Mazigo HD, Mahande MJ, Kweka EJ: Is aging raw cattle urine efficient for sampling Anopheles arabiensis Patton? BMC Infect Dis 2010, 10:172.

18. WHO: Manual on practical entomology in malaria. Part II. WHO Division of Malaria and Other Parasitic Diseases, Geneva 1975.

19. Ijumba JN: The impact of rice and sugarcane irrigation on malaria transmission in the lower Moshi area of northern Tanzania. Zoological Institute of Copenhagen Denmark, PhD thesis 1997.

20. Kikankie CK, Brooke BD, Knols BG, Koekemoer LL, Farenhorst M, Hunt RH, Thomas MB, Coetzee M: The infectivity of the entomopathogenic fungus Beauveria bassiana to insecticide-resistant and susceptible Anopheles arabiensis mosquitoes at two different temperatures. Malar J 2010, 9:71.

21. Malima RC, Oxborough RM, Tungu PK, Maxwell C, Lyimo I, Mwingira V, Mosha FW, Matowo J, Magesa SM, Rowland MW: Behavioural and insecticidal effects of organophosphate-, carbamate- and pyrethroidtreated mosquito nets against African malaria vectors. Med Vet Entomol 2009, 23:317-325.

22. N'Guessan R, Boko P, Odjo A, Knols B, Akogbeto M, Rowland M: Control of pyrethroid-resistant Anopheles gambiae and Culex quinquefasciatus mosquitoes with chlorfenapyr in Benin. Trop Med Int Health 2009, 14:389-395.

23. Romi R, Proietti S, Di Luca M, Cristofaro M: Laboratory evaluation of the bioinsecticide Spinosad for mosquito control. J Am Mosq Control Assoc 2006, 22:93-96.

24. Howard AF, Koenraadt CJ, Farenhorst M, Knols BG, Takken W: Pyrethroid resistance in Anopheles gambiae leads to increased susceptibility to the entomopathogenic fungi Metarhizium anisopliae and Beauveria bassiana. Malar J 2010, 9:168.

25. Atieli H, Menya D, Githeko A, Scott T: House design modifications reduce indoor resting malaria vector densities in rice irrigation scheme area in western Kenya. Malar J 2009, 8:108

26. Kirby MJ, Ameh D, Bottomley C, Green C, Jawara M, Milligan PJ, Snell PC, Conway DJ, Lindsay SW: Effect of two different house screening interventions on exposure to malaria vectors and on anaemia in children in The Gambia: a randomised controlled trial. Lancet 2009, 374:998-1009.

doi:10.1186/1756-3305-3-75

Cite this article as: Kweka et al:: Optimization of odour-baited resting boxes for sampling malaria vector, Anopheles arabiensis Patton, in arid and highland areas of Africa. Parasites \& Vectors 2010 3:75.

\section{Submit your next manuscript to BioMed Central and take full advantage of:}

- Convenient online submission

- Thorough peer review

- No space constraints or color figure charges

- Immediate publication on acceptance

- Inclusion in PubMed, CAS, Scopus and Google Scholar

- Research which is freely available for redistribution

Submit your manuscript at www.biomedcentral.com/submit 